\title{
PEMBERDAYAAN EKONOMI MELALUI PELATIHAN EKSPOR PADA KELOMPOK UMKM DAN SMK DI KELURAHAN DUREN JAYA KECAMATAN BEKASI TIMUR KOTA BEKASI PROVINSI JAWA BARAT
}

\author{
Kencana Verawati ${ }^{1}$, Henita Rahmayanti ${ }^{2}$ \\ ${ }^{1,2}$ Fakultas Teknik, Jurusan Teknik Sipil, Prodi Transportasi, Universitas Negeri Jakarta \\ e-mail: kencanaverawati@unj.ac.id, henita.rahmayanti@unj.ac.id
}

\begin{abstract}
Abstrak
Banyak pengusaha kecil dan menengah berharap mengembangkan bisnis dengan cara ekspor produknya ke pasar yang lebih luas. Namun demikian jarang ada pengusaha yang dapat terpikir untuk bisa mencoba pasar ekspor agar bisa memperluas jangkauan pasar mereka. Masalah pajak ini pun antara ekspor maupun impor memiliki peraturan yang berbeda. Saat kita mengimpor barang, hampir semua barang terkena pajak import. Sedangkan saat mengekspor produk kita ke luar negeri tidak semua produk dikenakan pajak ekspor dan bea cukai. Metode yang diguanakan yaitu (1) Persiapan (2) Pelaksanaan dan (3) Pelaporan. Berdasarkan evaluasi pelaksanaan kegiatan Penagbdian kepada Masyarakat (PkM) bahwa sosialisasi yang diikuti oleh 91 (Sembilan puluh satu) peserta telah memahami kegiatan ekspor dengan tingkat pemahaman kelulusan $100 \%$. Kegiatan berjalan dengan lancar, diikuti secara antusias oleh para peserta, dan menjadi pengalaman serta meningkatan kesadaran pentingnya mengetahui kegiatan ekspor di Indonesia untuk meningkatkan pengetahuan tentang aktifitas atau kegiatan logistik yaitu pengiriman dan distribusi barang.
\end{abstract}

Kata kunci: Ekspor, Peraturan, Pengiriman

\begin{abstract}
Many small and medium entrepreneurs hope to develop their business by exporting their products to a wider market. However, rarely do entrepreneurs think of being able to try out the export market in order to expand their market reach. Even this tax issue between exports and imports has different regulations. When we import goods, almost all goods are subject to import taxes. Meanwhile, when exporting our products overseas, not all products are subject to export taxes and customs duties. The methods used are (1) preparation (2) implementation and (3) reporting. Based on the evaluation of the implementation of PkM activities, the socialization that was attended by 91 (ninety one) participants had understood export activities with a passing level of $100 \%$ understanding. The activity ran smoothly, was followed enthusiastically by the participants, and became an experience and increased awareness of the importance of knowing export activities in Indonesia to
\end{abstract}


increase knowledge about logistical activities or activities, namely the delivery and distribution of goods.

Keywords : Export, Regulation, Delivery

\section{PENDAHULUAN}

Salah satu upaya yang serius yang coba dilakukan pemerintah dalam mengembangkan sektor Usaha Mikro Kecil dan Menengah (UMKM) sebagai salah satu solusi alternatif untuk mengembangkan kualitas sumber daya manusia dalam rangka penanggulangan angka kemiskinan dan pengangguran adalah dengan membentuk suatu lembaga khusus yang dalam tugas pokok dan fungsinya yang terkonsentrasi pada sektor Usaha Mikro Kecil dan Menengah (UMKM) tersebut.

Dinas

Perindustrian

Perdagangan dan Koperasi khususnya yang ada di Kota Bekasi merupakan salah satu perangkat Pemerintahan Daerah. Dalam beberapa tahun terakhir sektor Usaha Mikro Kecil Menengah (UMKM) telah berhasil menjelma menjadi sumber penggerak ekonomi baru di Indonesia. Tambunan (2012) mendefinisikan UMKM sebagai sebuah unit usaha yang mandiri dan berdiri sendiri, dimana dilakukan oleh orang perorangan atau Badan Usaha. Kontribusi UMKM terhadap Produk Domestik Bruto (PDB) tercatat mencapai 61,41 persen. Dengan dominasi tersebut, UMKM setidaknya menyerap hampir 97 persen total tenaga kerja nasional dan memiliki proporsi 99 persen dari total pelaku usaha di Indonesia.Maka tidak berlebihan apabila kita menyebut bahwa ekonomi di Indonesia tumbuh pesat lewat sektor UMKM. Peran UMKM terhadap perekonomian dan penyerapan tenaga kerja memang tidak lagi diragukan. Namun, dalam sektor perpajakan, UMKM belum mencerminkan kontribusi yang dominan sebagaimana pengaruhnya terhadap perekonomian dan penyerapan tenaga kerja. Pada tahun 2014, sumbangsih penerimaan pajak dari PPh Final UMKM hanya sekitar Rp2 triliun. Dengan asumsi UMKM berkontribusi Rp.3.000 trilliun terhadap PDB, nilai itu masih relatif jauh dibawah potensi perpajakan sebesar Rp30 triliun (1 persen dari kontrobusi terhadap PDB).

Salah satu upaya yang serius yang coba dilakukan pemerintah dalam mengembangkan sektor Usaha Mikro Kecil dan Menengah (UMKM) sebagai salah satu solusi alternatif untuk mengembangkan kualitas sumber daya manusia dalam rangka penanggulangan angka kemiskinan dan pengangguran adalah dengan membentuk suatu lembaga khusus yang dalam tugas pokok dan fungsinya yang terkonsentrasi pada sektor Usaha Mikro Kecil dan Menengah (UMKM) tersebut.

Dinas Perindustrian Perdagangan dan Koperasi khususnya yang ada di Kota Bekasi merupakan salah satu perangkat Pemerintahan Daerah, yang merupakan bagian dari 
suksesor implementasi kebijakan dan pelaksana pembangunan Pemerintah Kota Bekasi, dilahirkan untuk membantu pelaksanaan otonomi daerah, Dinas Perindustrian Perdagangan dan Koperasi ini bertanggung jawab untuk melaksanakan tugas dan fungsinya sesuai dengan Undang-Undang Republik Indonesia No. 20 Tahun 2008, yaitu bertugas lebih mentikberatkan kepada pelayanan publik dalam bidang pelayanan perindustrian perdagangan dan koperasi serta UMKM dalam memperlancar roda perekonomian, mendorong pertumbuhan kota melalui kegiatan jasa dan perdagangan. Pentingnya pelayanan tersebut untuk meningkatkan sentra-sentra industri perdagangan dan koperasi serta UMKM dalam menunjang Visi Kota Bekasi, yaitu BEKASI SEHAT, CERDA dan IHSAN sehingga kesejahteraan masyarakatnya dapat lebih terjamin dan tingkat pengangguran di Kota Bekasi ini pun dapat di minimalisir.

Menurut Mankiw (2006), ekspor adalah berbagai macam barang dan jasa yang diproduksi di dalam negeri lalu di jual di luar negeri. Berdasarkan Undang-Undang Nomor 17 Tahun 2006 tentang Perubahan Undang-Undang No. 10.

Tahun 1995 tentang Kepabeanan, ekspor adalah kegitan mengeluarkan barang keluar daerah pabean sesuai dengan UU Kepabeanan. Menurut Susilo (2008), impor bisa diartikan sebagai kegiatan memasukkan barang dari suatu negara (luar negeri) ke dalam wilayah pabean negara lain (dalam negeri). Pengertian ini memiliki arti bahwa kegiatan impor berarti melibatkan dua negara.

Dalam hal ini bisa diwakili oleh kepentingan dua perusahaaan antar dua negara tersebut, di mana satu pihak bertindak sebagai penjual (eksportir) dan satunya sebagai pembeli (importir). Sedangkan menurut Tanjung (2011), transaksi impor adalah perdagangan dengan cara memasukkan barang dari luar negeri ke dalam daerah pabean Indonesia dengan mematuhi ketentuan peraturan perudang-undangan yang berlaku. Menurut peraturan perundang undangan Impor adalah kegiatan memasukkan barang ke dalam daerah pabean.

Tujuan utama kegiatan pengabdian masyarakat ini adalah untuk meningkatkan wawasan dan pengetahuan pelaku UMKM (pengrajin rotan, fashion - penjahit, pedagang online / offline, pengrajin pengolahan kertas bekas), siswa, mahasiswa serta masyarakat umum untuk mengetahui kegiatan ekspor. Terutama untuk pelaku UMKM bahwa dengan perkembangan teknologi saat ini yang semakin canggih, pengiriman barang tidak hanya dilakukan di dalam Indonesia (perdagangan) melainkan dilakukan di dalam negeri dan ke luar negeri. Didukung oleh beberapa aplikasi atau program atau platform jual beli yang bisa diakses melalui telpon genggam atau $\mathrm{Hp}$ (handphone). Sehingga persaingan dalam perdagangan semakin meningkat. Hal ini dapat diatas dengan meningkatkan pemahamam UMKM untuk maju bersaing di dunia ekspor. 


\section{METODE}

Metode Metode yang digunakan adalah ceramah, simulasi, diskusi serta evaluasi. Metode pelaksanaan kegiatan pengabdian kepada masyarakat ini dilakukan dengan tiga tahapan pelaksanaan, yaitu:

\section{Persiapan}

Setelah mendapatkan rencana aksi maka dilakukan persiapan kegiatan pengabdian masyarakat.

2. Pelaksanaan kegiatan

Kegiatan pengabdian ini dilaksanakan untuk menindakanjuti rencana kegiatan dengan memberikan sosialisasi atau pelatihan kepada pelaku UKM, siswa SMK 6 Bekasi dan masyarakat umum.

3. Pelaporan

Program ini merupakan menyusun laporan kegiatan pengabdian masyarakat yang telah dilakukan dengan memberikan sosialisasi pengetahuan tentang ekspor untuk meningkatkan pengetahuan para pelaku UMKM, siswa SMK 6 Bekasi dan masyarakat umum.

\section{HASIL DAN PEMBAHASAN}

Hasil pengabdian kepada masyarakat ini mendapatkan beberapa hasil yang diharapkan mempunyai efek positif bagi mitra. Kegiatan PkM ini dibagi menjadi tiga tahap, yaitu: tahap persiapan, pelaksanaan, dan pelaporan. Kegiatan pada tahap persiapan, kegiatan PkM (Pengabdian kepada masyarakat) telah direncanakan dari bulan Maret sampai minggu ketiga September.

Tim PkM merumuskan masalah yang terjadi di masyarakat terkait dengan ketidaktahuan ilmu pengetahuan tentang ekspor. Setelah permasalahan ditemukan, maka selanjutnya disusun proposal untuk diajukan ke LPPM melalui SIPP (Sistem Informasi Penelitian dan Pengabdian Masyarakat) LPPM UNJ.

Setelah melalui proses review internal, maka pada awal Mei diumumkan bahwa tim ini termasuk dalam penerima hibah kegiatan PkM Fakultas. Oleh karena itu langkah selanjutnya adalah berkoordinasi dengan mitra, dalam hal ini SMKN 6 Kota Bekasi yang akan menjadi tuan rumah pelaksanaan kegiatan. Kepala SMKN 6 Kota Bekasi dan para siswa SMK sangat menyambut baik hal ini. Awalnya kegiatan PkM ini akan diadakan secara langsung di tempat mitra, yaitu SMKN 6 Kota Bekasi. Namun dikarenakan adanya wabah Covid-19, maka pelaksanaan PkM dilaksanakan secara online dengan tetap penyelenggaraan pusat di Lab. RPL SMKN 6 Kota Bekasi.

Kemudian disepakati waktu pelaksanaan pada awal bulan Juli 2020 , tepatnya pada tanggal 07 Juli 2020. Waktu yang panjang menuju pelaksanaan kegiatan dimanfaatkan untuk mempersiapkan acara, mulai dari: membuat bahan / materi, pembagian tugas panitia, serta mengundang calon peserta yang akan terlibat. Waktu yang panjang menuju pelaksanaan kegiatan dimanfaatkan untuk mempersiapkan acara, mulai dari: menyiapkan materi, pembagian tugas panitia, mengundang calon peserta hingga mengarahkan mahasiswa yang akan terlibat.

Pada pelaksanaan kegiatan ini dihadiri dan diikuti oleh siswa SMKN 6 
Bekasi, Pelaku UMKM, Mahasiswa dan Dosen. Dengan rincian sebagai berikut : UMKM (pengrajin rotan, fashion penjahit, pedagang online / offline, pengrajin pengolahan kertas bekas), SMPN 11 Kota Bekasi, SMK Negeri 6 Kota Bekasi, SMK Negeri 5 kota Bekasi, SMK Negeri 47 Jakarta, Universitas Negeri Jakarta, Universitas Singaperbangsa Karawang, Universitas Muhammadiyah Prof. Dr. Hamka, Universitas YARSI, Universitas M.H Thamrin, Universitas Katolik Parahyangan, Universitas Dian Nusantara, Universitas Nasional, Universitas Indonesia, Universitas Gunadarma, Universitas Paramadina, masyarakat sekitar sekolah SMK N 6 Bekasi serta Inspektorat Jenderal Kementerian Perhubungan, dan PPSDM KEBTKE.

Pembukaan diawali oleh pengisian presensi dan peserta mengikuti pre-test. Soal pre-test terdiri dari 10 soal berupa pilihan ganda yang berkaitan dengan pengetahuan topik yang akan dibahas dalam sosialisasi. Berikut Grafik hasil pre-test para peserta.

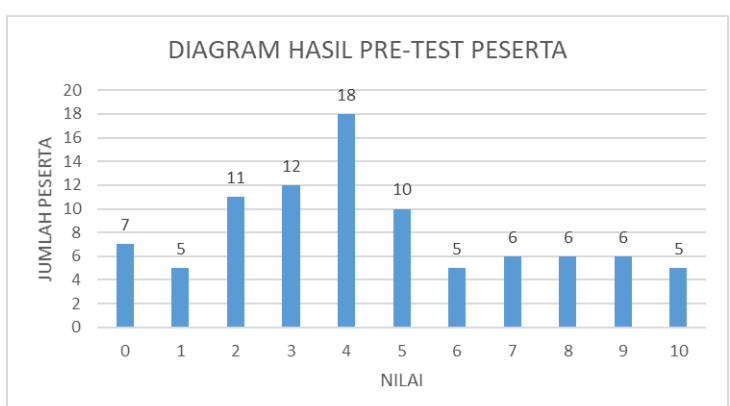

Gambar 1. Diagram Hasil Pre-Test Peserta Pelatihan Ekspor
Dari grafik diatas dapat diidentifikasi bahwa peserta banyak mendapatkan nilai dibawah 7 (tujuh) yaitu sebanyak 68 peserta atau $75 \%$ sedangkan sebanyak 23 peserta atau $25 \%$ sudah memahami kegiatan ekspor. Jika nilai dibawah 7 (tujuh) artinya peserta belum memahami dengan baik bagaimana sistem kegiatan ekspor di Indonesia. Hal ini juga menjadi tolak ukur agar dengan adanya sosialisasi ini, peserta dapat memahami dengan baik proses atau alur dari sistem ekpor, kebijakan, persyaratan dan sebagainya.

Setelah mengikuti pelatihan para peserta diberikan soal post-test untuk mengetahui apakah ada peningkatan pengetahuan peserta tentang materi yang dijelaskan. Soal post-test terdiri dari 10 soal. Soal post-test yang berikan sama seperti yang diberikan saat pre-test. Berdasarkan hasil posttest dapat dilihat bahwa adanya peningkatan pemahaman peserta mengenai materi pelatihan yang dijelaskan.

Kegiatan dilakukan dengan memberikan materi melalui aplikasi zoom, metode penyampaian 2 arah (pemateri dan peserta). Simulasi dengan memberikan gambar alur dari kegiatan ekspor di Indonesia dengan membahas dokumen- dokumen serta persyaratan dari satu kegiatan ke kegiatan lainnya. Peserta juga dilatih untuk memberikan contoh dari bidang pekerjaan / bisnis yang sudah ditekuni ataupun yang belum (masih mempunyai rencana), hal ini dilakukan agar mereka paham dengan bisnis yang akan dijalankan jika melakukan ekspor. Diakhir sosialisasi, peserta 
wajib mengikuti post test yang berguna untuk mengetahui peningkatan pemahaman mereka tentang kegiatan bisnis ekspor. Post test diikuti oleh 91 peserta dengan soal 10 butir. Hasil yang diperoleh setelah diolah hasil post test peserta didapat sebanyak 91 peserta mendapatkan nilai 7 (tujuh) sebanyak 31 peserta, nilai 8 (delapan) sebanyak 23 peserta, nilai 9 (Sembilan) sebanyak 26 peserta dan nilai 10 (sepuluh) sebanyak 11 peserta. Dengan hal tersebut dapat disimpulkan bahwa seluruh peserta 100\% mengalami peningkatan pemahaman tentang kegiatan ekspor.

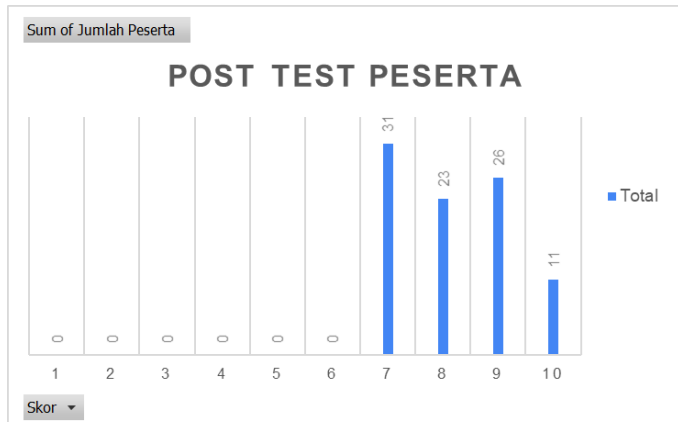

Gambar 2. Diagram Hasil Post-Test Peserta Pelatihan Ekspor

Setelah mengerjakan post-test, peserta diberikan pertanyaan mengenai evaluasi pelaksanaan pelatihan. Berdasarkan hasil evaluasi pelaksanaan yang diberikan kepada para peserta disebutkan bahwa penjelasan yang diberikan pemateri sangat jelas dan mudah dipahami. Waktu yang pelaksanaan juga sudah sangat sesuai dengan materi yang dipaparkan.
Berdasarkan hasil evaluasi juga disebutkan bahwa para peserta menginginkan kelanjutan kegiatan pelatihan dengan topik-topik di bidang transportasi. Topik-topik tersebut dibutuhkan karena pelatihan di bidang transportasi jarang di dapat oleh para siswa SMK.

Selain itu kegiatan pengabdian masyarakat juga mendapatkan kritik, antara lain gangguan sinyal karena kondisi saat ini Covid19 sehingga dilakukan pelatihan secara online menggunakan Zoom, materi yang sedang ditampilkan terlambat tayang. Hal ini akan kami perhatikan lagi untuk perbaikan pelaksanaan pengabdian masyarakat di masa depan terutama jika saat ditampila menggunakan sistem online. Setelah mengikuti kegiatan ini, para peserta diberikan emateri dan e-sertifikat. Sedangkan untuk publikasi di media Youtube dilakukan upload hasil sosialisasi.

\section{KESIMPULAN}

Berdasarkan hasil dan pembahasan terhadap pelaksanaan kegiatan PkM maka dapat disimpulkan sebagai berikut: (a) Kegiatan PkM ini adalah pelatihan ekspor kepada pelaku UMKM dan siswa SMK 6 BEKASI, mahasiswa, dosen dan umum. (b) Kegiatan PkM telah dilaksanakan di SMKN 6 Kota Bekasi pada tanggal 07 Juli 2020 dan dihadiri oleh 50 yang terdiri dari siswa, mahasiswa, dosen, unit pemerintahan dan pelaku UMKM dari wilayah Jabodetabek dan Jawa Barat. (c) Kegiatan berjalan dengan lancar, diikuti secara antusias oleh para peserta, dan menjadi pengalaman serta meningkatan kesadaran pentingnya 
mengetahui kegiatan ekspor di Indonesia untuk meningkatkan pengetahuan tentang aktifitas atau kegiatan logistik yaitu pengiriman dan distribusi barang. (d) Pelaksanaan program mampu menghasilkan luaranluaran yang diharapkan oleh program pengabdian kepada masyarakat ini.

\section{DAFTAR PUSTAKA}

Amir M.S, 2001, Ekspor Impor: Teori \& Penerapannya, Jakarta: PPM.

Amir M.S, 1993, Seluk-beluk dan Tehnik Perdagangan Luar Negeri: Suatu Penuntun IMPOR \& EKSPOR, Jakarta: PT Pustaka.

Chairul Anwar, 2001, Hukum Perdagangan Internasional, Jakarta: Novindo Pustaka Mandiri.

Gunawan Widjaja \& Ahmad Yani, 2001, Seri Hukum Bisnis. Transaksi Bisnis Internasional (EksporImpor), Jakarta: Raja Grafindo Persada.

Mankiw, N,Gregory, 2006. Makro Ekonomi, Terjemahan: Fitria Liza, Imam Nurmawan, Jakarta: Penerbit Erlangga.

Mardiasmo, 2016. Perpajakan Edisi Revisi Tahun 2016. Yogyakarta:Penerbit Andi.

Munir Fuady, 2003, Hukum Kontrak (Dari Sudut Pandang Hukum Bisnis), Bandung: Citra Aditya Bakti.

Raflis, R., Wijaya, R. S., \& Rahmi, Y. Y, 2019. Pelatihan Penerapan Akuntansi Dan Pajak Pada Badan Usaha Milik Nagari
Barokah Lamo Kabupaten Sijunjung. Dinamisia: Jurnal Pengabdian Kepada Masyarakat, 3.

Raharjo, T., \& Khusnaini, K, 2018. Asistensi Pembuatan Laporan Keuangan Berbasis Android bagi Usaha Mikro, Kecil, dan Menengah. Wikrama Parahita: Jurnal Pengabdian Masyarakat, 2(2), 75-78.

Resmi,Siti. 2013. Perpajakan Teori dan Kasus. Salemba Empat. Jakarta.

Snieska, V. dan Normantiene, A., 2011, The Role of Creative Industries in International Rate, Economics and Management, vol. 16.

Susilo, Andi, 2008.Buku Pintar EksporImpor, Trans Media Pustaka.

Tambunan, Tulus, 2012. "Usaha Mikro Kecil dan Menengah di Indonesia : isu-isu penting", Jakarta : LP3ES.

Tanjung, Abdul Hafiz, 2011. Akuntansi, Transparansi, dan Akuntabilitas Keuangan Publik (Sebuah Tantangan).

Undang-Undang Nomor 17 Tahun 2006 tentang Perubahan UndangUndang No. 10 Tahun 1995 tentang Kepabeanan.

Undang-Undang Nomor 28 Tahun 2007 tentang Ketentuan Umum dan Tata Cara Perpajakan.

Waluyo, 2011, Perpajakan Indonesia. Jakarta: Salemba Empat.

Windari, Ratna Artha, 2014, Hukum Perjanjian, Yogyakarta: Graha Ilmu. 